\title{
Prevention of Diabetic Glomerulopathy by Pharmacological Amelioration of Glomerular Capillary Hypertension
}

\author{
Roberto Zatz, B. Rentz Dunn, Timothy W. Meyer, Sharon Anderson, Helmut G. Rennke, and Barry M. Brenner \\ With the technical assistance of J. L. Troy, R. L. DeGraphenried, J. L. Noddin, A. W. Nunn, and D. Sandstrom \\ Laboratory of Kidney and Electrolyte Physiology and Departments of Medicine and Pathology, Brigham and Women's Hospital and \\ Harvard Medical School, Boston, Massachusetts 02115
}

\begin{abstract}
Two groups of adult male Munich-Wistar rats and a third group of nondiabetic age-matched and weight-matched normal control rats underwent micropuncture study $1 \mathrm{mo}$, and morphologic studies 14 mo, after induction of streptozotocin diabetes or sham treatment. All animals were fed standard rat chow. Diabetic rats received daily ultralente insulin to maintain stable moderate hyperglycemia $(\sim 350 \mathrm{mg} / \mathrm{dl})$. In addition, one group of diabetic rats was treated with the angiotensin I converting enzyme inhibitor, enalapril, $15 \mathrm{mg} /$ liter of drinking water. Average kidney weight, whole kidney and single-nephron glomerular filtration rate, and glomerular plasma flow rate were elevated to similar values in both groups of diabetic rats, relative to normal control rats. Non-enalapril-treated diabetic rats exhibited significant elevations in mean glomerular capillary hydraulic pressure and transcapillary hydraulic pressure gradient, compared with the other groups studied, and only this group eventually developed marked and progressive albuminuria. Likewise, histological examination of the kidneys at 14 mo disclosed a high incidence of glomerular structural abnormalities only in non-enalapril-treated diabetic rats. These findings indicate that prevention of glomerular capillary hypertension in rats with diabetes mellitus effectively protects against the subsequent development of glomerular structural injury and proteinuria. This protection is afforded despite pronounced hyperglycemia and elevated levels of glucosylated hemoglobin, further supporting our view that hemodynamic rather than metabolic factors predominate in the pathogenesis of diabetic glomerulopathy.
\end{abstract}

\section{Introduction}

A state of glomerular hyperfiltration has been consistently demonstrated in patients with newly diagnosed insulin-dependent (Type I) diabetes mellitus (DM) ${ }^{1}(1-4)$, as well as in the early

Portions of this work were presented at the 17th and 18th Annual Meetings of The American Society of Nephrology, Washington, DC, December 1984; and New Orleans, LA, December, 1985; and were published in abstract form, 1985, Kidney Int., 27:252A; and 1986, Kidney Int., 29: 328.

Address reprint requests to Dr. Brenner, Director, Renal Division, Department of Medicine, Brigham and Women's Hospital, 75 Francis St., Boston, MA 02115.

Received for publication 26 November 1985 and in revised form 25 February 1986.

1. Abbreviations used in this paper: $\overline{\Delta \mathrm{P}}$, glomerular transcapillary hydraulic pressure difference; $\pi_{\mathrm{A}}$, systemic plasma colloid osmotic pressure;

J. Clin. Invest.

(C) The American Society for Clinical Investigation, Inc.

$0021-9738 / 86 / 06 / 1925 / 06 \quad \$ 1.00$

Volume 77, June 1986, 1925-1930 stages of experimental diabetes in animals (5-7). In the latter, this hyperfiltration has been shown to result from concomitant elevations in glomerular plasma flow rate $\left(Q_{\mathrm{A}}\right)$ and mean glomerular capillary hydraulic pressure (5-7). These early glomerular hemodynamic abnormalities have been implicated in the pathogenesis of the glomerulopathy that eventually develops in this disorder $(8,9)$. We have shown previously $(7)$ that in rats with diabetes induced by streptozotocin (STZ), dietary protein restriction limits both early elevations in glomerular pressures and flows and the subsequent development of glomerular structural injury. Moreover, glomerular structural injury can be effectively prevented despite pronounced hyperglycemia as long as glomerular pressures and flows are maintained within normal limits. These findings provide strong evidence that hemodynamic, rather than metabolic, factors play a fundamental role in the initiation and progression of diabetic glomerulopathy.

Limitation of glomerular hemodynamic alterations has also been shown to prevent glomerular injury in rats subjected to severe renal ablation. Hostetter and co-workers (10) showed that dietary protein restriction normalizes glomerular hemodynamics and completely arrests glomerular injury in rats following 11/ 12 renal ablation. More recentiy, Anderson and co-workers (11), using rats with $5 / 6$ renal ablation, demonstrated that treatment with the potent angiotensin I converting enzyme inhibitor, enalapril, not only restores systemic arterial pressure to normal levels but also selectively normalizes mean glomerular capillary hydraulic pressure. $8 \mathrm{wk}$ after renal ablation, enalapril-treated rats exhibited a striking attenuation of glomerular structural injury, thus strengthening the possibility that glomerular hemodynamic abnormalities, and in particular elevations in glomerular pressures, also play a key role in the pathogenesis of diabetic glomerulopathy.

Systemic hypertension has been demonstrated to worsen, while antihypertensive therapy ameliorates, the progression of established diabetic glomerulopathy (12-14). However, administration of antihypertensive therapy to normotensive diabetic patients has never been attempted as a prophylactic measure against glomerular disease. Since the kidneys of diabetic subjects exhibit marked vasodilation, it seems likely that even slight reductions in systemic arterial pressure would reduce glomerular

$\overline{\mathrm{AP}}$, mean arterial pressure under anesthesia at time of micropuncture study; C, control; DM, diabetes mellitus; DM+E, insulin-treated rats also receiving enalapril; GFR, glomerular filtration rate; $\mathrm{HbA}_{\mathbf{l c}}$, glucosylated hemoglobin; $K_{\mathrm{f}}$, glomerular capillary ultrafiltration coefficient; LKW, left kidney weight; PAS, periodic acid Schiff; $\overline{\mathrm{P}}_{\mathrm{GC}}$, mean glomerular capillary hydraulic pressure; $Q_{\mathrm{A}}$, glomerular plasma flow rate; $R_{\mathrm{A}}$, afferent artereriolar resistance; $R_{\mathrm{E}}$, efferent arteriolar resistance; $R_{\mathrm{T}}$, total arteriolar resistance; SBP, systolic blood pressure determined directly from the femoral artery under anesthesia at time of micropuncture study; SNFF, single-nephron filtration fraction; SNGFR, single-nephron glomerular filtration rate; STZ, streptozotocin; TBP, awake systolic blood pressure measured by tail cuff; $\mathrm{U}_{\mathrm{alb}} \cdot \mathrm{V}$, urinary albumin excretion rate. 
Table I. Systemic Hemodynamic and Whole Kidney Parameters at 4-6 Wk of Diabetes

\begin{tabular}{llllllll}
\hline Group & Body weight & LKW & BG & TBP & SBP & $\overline{\text { AP }}$ & GFR \\
\hline & $g$ & $g$ & $m g / d l$ & $m m H g$ & $m m H g$ & $m m H g$ & $m l / m i n$ \\
C $(n=7$ rats $)$ & $291 \pm 7$ & $1.09 \pm 0.03$ & $87 \pm 3$ & $137 \pm 4$ & $147 \pm 4$ & $119 \pm 3$ & $1.34 \pm 0.07$ \\
DM $(n=8)$ & $280 \pm 6$ & $1.47 \pm 0.04^{*}$ & $350 \pm 11^{*}$ & $138 \pm 5$ & $139 \pm 3$ & $117 \pm 4$ & $1.84 \pm 0.09^{*}$ \\
DM + E $(n=8)$ & $277 \pm 3$ & $1.31 \pm 0.04^{*} \ddagger$ & $346 \pm 14^{*}$ & $117 \pm 3^{*} \ddagger$ & $124 \pm 4^{*} \ddagger$ & $98 \pm 2^{*} \ddagger$ & $1.58 \pm 0.14^{*}$ \\
\hline
\end{tabular}

Values given as mean \pm 1 SEM. ${ }^{*} P<0.05$ vs. $\mathrm{C} ; \ddagger P<0.05$ vs. DM.

capillary hydraulic pressure and thereby prevent the subsequent development of glomerular injury in this model, even in the setting of pronounced and longstanding hyperglycemia. Accordingly, the present study was undertaken to test this hypothesis and to dissociate the specific deleterious effects of hemodynamic abnormalities from any hypothetical effects of deranged metabolism per se.

\section{Methods}

We used 57 adult male Munich-Wistar rats in this study. 39 rats were made diabetic by a single i.v. injection of STZ $(60 \mathrm{mg} / \mathrm{kg})$ under light anesthesia. Morning glucose concentration was determined biweekly on tail blood samples with a reflectance meter (Miles Ames Div., Miles Laboratories, Inc., Elkhart, IN). Rats received daily evening injections of a heat-treated ultralente insulin (NOVO Industrie, Copenhagen, Denmark) $(7,15)$, individually adjusted to maintain blood glucose concentration between 200 and $400 \mathrm{mg} / \mathrm{dl}$. Daily insulin dose averaged $\sim 0.8$ U. Normal control rats matched for initial age and weight were also studied. 3-7 d after STZ injection, diabetic rats were randomly assigned to either of two groups: $(a) \mathrm{DM}$, rats receiving no other therapy than exogenous insulin, and $(b) \mathrm{DM}+\mathrm{E}$, insulin-treated rats also receiving enalapril (Merck, Sharp, and Dohme, West Point, PA), $15 \mathrm{mg} / \mathrm{liter}$ in the drinking water.

16 diabetic rats and 7 control rats underwent micropuncture study 4-6 wk after STZ injection. Blood glucose concentration was measured shortly before the beginning of each experiment and a few rats with values below $200 \mathrm{mg} / \mathrm{dl}$ were excluded from micropuncture study. Additional determinations made throughout the duration of these studies verified the persistence of moderate hyperglycemia $(300-400 \mathrm{mg} / \mathrm{dl})$. Rats were anesthetized with Inactin $(100 \mathrm{mg} / \mathrm{kg})$ and prepared for micropuncture as described previously (16). To replace plasma losses associated with anesthesia and surgery (17), isoncotic homologous plasma obtained from normal rats, equivalent to $1 \%$ body weight in volume, was infused over 50-60 min, followed by a sustaining infusion of $0.8-$ $1.0 \mathrm{ml} / \mathrm{h}$ throughout the rest of the experiment. Inulin, $10 \mathrm{~g} / 100 \mathrm{ml}$ in normal saline, was also infused at a rate of $1.2 \mathrm{ml} / \mathrm{h}$. Samples of tubule fluid were obtained from superficial proximal tubules for determinations of flow rate and inulin concentration. The latter was measured by the method of Vurek and Pegram (18). Blood samples were obtained from surface efferent arterioles for determination of total protein concentration as described previously $(16,19)$. Hydraulic pressures were measured in superficial cortical tubules and microvessels by the servo-null technique (16). Details of the calculations employed are given elsewhere (16).

Rats in each group not subjected to micropuncture study were maintained at similar stable levels of moderate hyperglycemia by daily ultralente insulin treatment for 14 mo after induction of diabetes. 24-h urinary albumin excretion rates were determined at alternate monthly intervals by the single radial immunodiffusion technique (20). Systolic blood pressures were also measured by tail cuff (TBP) at biweekly intervals in these conscious rats. At the end of this 14-mo period, rats were anesthetized with nembutal $(50 \mathrm{mg} / \mathrm{kg}$ i.p.) and $150 \mu \mathrm{l}$ of blood were collected for determination of glucosylated hemoglobin levels (21). Kidneys were then fixed by perfusion at the measured arterial pressure for 2-3 min with $1.25 \%$ glutaraldehyde in $0.1 \mathrm{M}$ sodium cacodylate buffer ( $\mathrm{pH} 7.4$ ).

Morphology. After perfusion fixation, the weight of the left kidney was recorded and two midcoronal slices of tissue, 2-3-mm thick, were processed for light microscopic examination. 3- $\mu \mathrm{m}$-thick paraffin sections were stained with hematoxylin and eosin and by the periodic acid Schiff (PAS) reaction. The extent of the glomerular damage was determined on PAS-stained slides by counting on two sections all glomerular profiles with segmental or global collapse of capillaries with or without associated hyalin deposition and adhesion of the tuft to Bowman's capsule. The number of glomeruli with segmental or global obsolescence of capillaries was expressed as a percentage of all glomerular profiles counted in the histologic sections. Structural alterations at the level of the tubules, interstitium, and blood vessels were assessed qualitatively.

Statistics. Statistical analysis was performed by one-way analysis of variance followed by Bonferroni's procedure for multiple pairwise comparisons (22).

\section{Results}

Micropuncture experiments. Values for systemic hemodynamic and whole kidney function 4-6 wk after STZ injection are presented in Table I (mean \pm 1 SEM). Both enalapril-treated $(\mathrm{DM}+\mathrm{E})$ and untreated (DM) diabetic rats exhibited body weights nearly identical to those of normal control rats. Blood glucose concentration determined immediately before micropuncture was moderately elevated as compared with controls $(87 \pm 3 \mathrm{mg} / \mathrm{dl})$ in both $\mathrm{DM}(350 \pm 11 \mathrm{mg} / \mathrm{dl})$ and DM+E $(346 \pm 14$ $\mathrm{mg} / \mathrm{dl}$ ) rats. Systolic blood pressure determined directly from the femoral artery (SBP) at the time of the experiment was similar in control $(\mathrm{C})$ and $\mathrm{DM}$ rats and did not differ from previously measured awake tail-cuff blood pressures (TBP) in either group (Fig. 1). A $20-\mathrm{mmHg}$ reduction in average SBP relative to $\mathrm{C}$ or

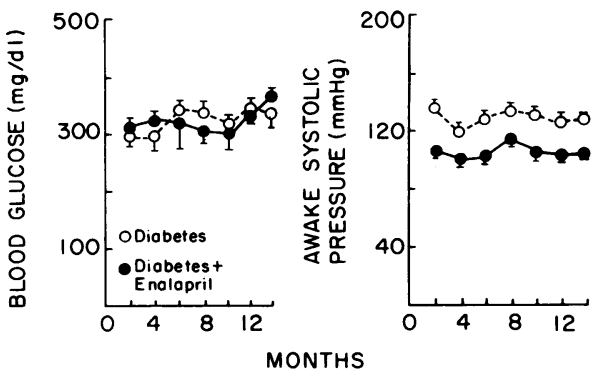

Figure 1. Alternate monthly average values for morning blood glucose concentration and awake systolic blood pressures in untreated and enalapril-treated diabetic rats. Blood glucose concentration was maintained at stable moderately elevated levels throughout the study in both groups by daily ultralente insulin treatment. Awake systolic blood pressures remained persistently lower in enalapril treated rats. 
Table II. Glomerular Hemodynamics after 4-6 Wk of Diabetes

\begin{tabular}{|c|c|c|c|c|c|c|c|c|c|c|c|c|c|c|c|c|}
\hline Group & SNGFR & $Q_{\text {A }}$ & SNFF & $R_{\text {A }}$ & $R_{\mathrm{E}}$ & $R_{\mathrm{T}}$ & $R_{\mathfrak{N}} / R_{\mathrm{T}}$ & $\overline{\mathbf{P}}_{\mathbf{C C}}$ & $\mathbf{P}_{\mathbf{T}}$ & $P_{E}$ & $\overline{\Delta \mathbf{P}}$ & $C_{\mathbf{A}}$ & $C_{\mathrm{E}}$ & $\pi_{A}$ & $\pi_{E}$ & $K_{\mathrm{f}}$ \\
\hline & $n l / \min$ & $n l / \min$ & \multicolumn{5}{|c|}{$\times 10^{10}$ dyne $\cdot \mathrm{s} \cdot \mathrm{cm}^{-5}$} & $m m H g$ & $m m H g$ & $m m H g$ & $m m H g$ & $g / d l$ & $g / d l$ & $m m H g$ & $m m H g$ & $n l /(s \cdot m m H g)$ \\
\hline $\mathrm{C}$ & 45.9 & 154 & 0.31 & 2.13 & 1.41 & 3.54 & 0.59 & 53 & 13 & 15 & 39 & 5.6 & 8.2 & 18.5 & 33.3 & 0.070 \\
\hline ( $n=7$ rats $)$ & \pm 3.8 & \pm 18 & \pm 0.02 & \pm 0.40 & \pm 0.21 & \pm 0.61 & \pm 0.02 & \pm 1 & \pm 0.2 & \pm 0.6 & \pm 1 & \pm 0.2 & \pm 0.3 & \pm 0.8 & \pm 1.8 & \pm 0.018 \\
\hline DM & 81.6 & 269 & 0.31 & 0.89 & 1.00 & 1.90 & 0.47 & 63 & 11 & 15 & 52 & 5.9 & 8.6 & 19.7 & 36.0 & 0.057 \\
\hline$(n=8)$ & $\pm 5.7^{*}$ & $\pm 26^{*}$ & \pm 0.02 & $\pm 0.13^{*}$ & \pm 0.12 & $\pm 0.21^{*}$ & $\pm 0.03^{*}$ & $\pm 2 *$ & $\pm 0.4^{*}$ & \pm 1 & $\pm 2 *$ & \pm 0.1 & \pm 0.3 & \pm 0.4 & \pm 1.8 & \pm 0.005 \\
\hline $\mathrm{DM}+\mathrm{E}$ & 71.9 & 227 & 0.31 & 0.92 & 0.76 & 1.68 & 0.55 & 50 & 12 & 17 & 37 & 5.3 & 7.8 & 17.1 & 30.7 & 0.101 \\
\hline$(n=8)$ & $\pm 7.2^{*}$ & $\pm 14^{*}$ & \pm 0.01 & $\pm 0.07^{*}$ & $\pm 0.04^{*}$ & $\pm 0.10^{*}$ & $\pm 0.02 \ddagger$ & $\pm 1 \ddagger$ & $\pm 0.3 \ddagger$ & \pm 0.6 & $\pm 1 \ddagger$ & $\pm 0.1 \ddagger$ & \pm 0.2 & $\pm 0.3 \ddagger$ & \pm 1.2 & \pm 0.017 \\
\hline
\end{tabular}

Abbreviations used in this table: $\mathrm{P}_{\mathrm{T}}$, proximal tubule hydraulic pressure; $\mathrm{P}_{\mathrm{E}}$, efferent arteriolar hydraulic pressure; $C_{\mathrm{A}}$, afferent (systemic) arteriolar total plasma protein concentration; $C_{\mathrm{E}}$, efferent arteriolar total plasma protein concentration; $\boldsymbol{\pi}_{\mathrm{E}}$, efferent arteriolar plasma colloid osmotic pressure. Values given as mean $\pm 1 \mathrm{SEM}$. $\boldsymbol{P}$ $<0.05$ vs. $\mathrm{C} ; \ddagger P<0.05$ vs. DM.

$D M$ values was observed in enalapril-treated $(D M+E)$ rats; once again, values for SBP were similar to previously measured TBP. Mean arterial pressure $(\overline{\mathrm{AP}})$ was nearly identical in $\mathrm{DM}$ and $\mathrm{C}$ rats $(117 \pm 4 \mathrm{mmHg}$ vs. $119 \pm 3 \mathrm{mmHg}$, respectively) while significantly decreased in $\mathrm{DM}+\mathrm{E}$ rats $(98 \pm 2 \mathrm{mmHg}, P<0.05)$.

A marked increase in left kidney weight (LKW) was seen in DM rats as compared with controls $(1.47 \pm 0.04 \mathrm{~g}$ vs. $1.09 \pm 0.03$ $\mathrm{g}, P<0.05)$. Less pronounced renal hypertrophy $(1.31 \pm 0.04 \mathrm{~g})$ was noted in DM+E rats. A similar pattern was observed with respect to whole-kidney glomerular filtration rate (GFR), with group DM exhibiting the highest average GFR value, blunted only slightly by enalapril treatment (Table I).

Results concerning glomerular hemodynamics are summarized in Table II and Fig. 2. As with GFR, the average value for single-nephron glomerular filtration rate (SNGFR) was markedly increased in DM rats $(81.6 \pm 5.7 \mathrm{nl} / \mathrm{min}$ vs. $45.9 \pm 3.8$ $\mathrm{nl} / \mathrm{min}$ in controls, $P<0.01$ ). This elevation in SNGFR was associated with a proportional increase in $Q_{\mathrm{A}}(269 \pm 26 \mathrm{nl} / \mathrm{min}$ vs. $154 \pm 18 \mathrm{nl} / \mathrm{min}$ in controls, $P<0.01$ ), hence constancy of single-nephron filtration fraction, SNFF. Since $\overline{\mathrm{AP}}$ was virtually identical in DM and $\mathrm{C}$ groups, the increase in $Q_{\mathrm{A}}$ must have resulted from renal arteriolar vasodilatation. Afferent $\left(R_{\mathrm{A}}\right)$, efferent $\left(R_{\mathrm{E}}\right)$, and total $\left(R_{\mathrm{T}}=R_{\mathrm{A}}+R_{\mathrm{E}}\right)$ arteriolar resistances were indeed markedly decreased in DM rats relative to controls. However, the observed fall in $R_{\mathrm{A}}$ was more pronounced than in $R_{\mathrm{E}}$, resulting in a decrease in the ratio $R_{\mathrm{A}} / R_{\mathrm{T}}$. In consequence, mean glomerular capillary hydraulic pressure $\left(\overline{\mathrm{P}}_{\mathrm{GC}}\right)$ and the glomerular transcapillary hydraulic pressure difference $(\overline{\Delta \mathrm{P}})$ were
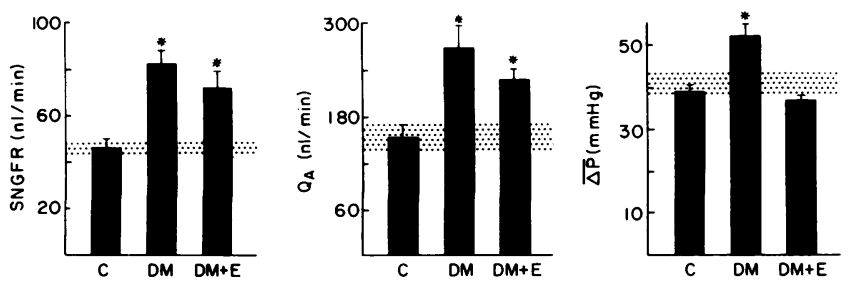

Figure 2. Glomerular hemodynamics 4-6 wk after induction of diabetes. SNGFR and $Q_{A}$ were augmented in diabetic rats (group DM) and not significantly affected by enalapril treatment (group DM+E), compared to non-diabetic control rats (group $C$ ). $\overline{\Delta \mathrm{P}}$ was also elevated in DM rats but was normalized by enalapril treatment. The stippled horizontal bands denote normal values $( \pm 1$ SEM) observed in this laboratory. markedly increased in DM rats $(63 \pm 2$ and $52 \pm 2 \mathrm{mmHg}$, respectively, vs. $53 \pm 1$ and $39 \pm 1 \mathrm{mmHg}$ in controls). Since values for the glomerular capillary ultrafiltration coefficient $\left(K_{f}\right)$ (see below) and systemic plasma colloid osmotic pressure $\left(\pi_{A}\right)$ were not significantly different in DM and $\mathrm{C}$ groups, the increase in SNGFR in DM rats can be attributed to the concomitant elevations observed in $Q_{\mathrm{A}}$ and $\overline{\Delta \mathrm{P}}$.

Enalapril-treated $(\mathrm{DM}+\mathrm{E})$ rats also exhibited a significant increase in LKW as compared with controls $(1.31 \pm 0.04 \mathrm{~g}$ vs. $1.09 \pm 0.03 \mathrm{~g}, P<0.05$, Table I). However, this hypertrophy was not as marked as in DM rats $(P<0.05 \mathrm{DM}$ vs. DM+E). GFR and SNGFR were numerically, though not significantly, lower in $\mathrm{DM}+\mathrm{E}$ when compared with $\mathrm{DM}$ rats. Since $R_{\mathrm{T}}$ in $\mathrm{DM}+\mathrm{E}$ rats was comparable to the average value obtained in DM rats, and given a moderate reduction in $\overline{\mathrm{AP}}, Q_{\mathrm{A}}$ was also slightly, but not significantly, diminished in this group relative to $D M$ rats. As a result of the reduction in $\overline{\mathrm{AP}}$ and a slight decrement in $R_{\mathrm{E}}$, $\overline{\Delta \mathrm{P}}$ was markedly decreased in $\mathrm{DM}+\mathrm{E}$ as compared with $\mathrm{DM}$ rats; in fact, $\overline{\Delta P}$ achieved complete normalization in $\mathrm{DM}+\mathrm{E}$ animals $(37 \pm 1 \mathrm{mmHg}$ vs. $39 \pm 1 \mathrm{mmHg}$ in controls). A unique value for $K_{\mathrm{f}}$ could be calculated in every experiment; no significant differences in this parameter were seen among the three groups studied, although $\mathrm{DM}+\mathrm{E}$ rats tended to have higher values (Table II).

Long-term studies. Results obtained for body weight, LKW (after perfusion-fixation with glutaraldehyde), glucosylated hemoglobin $\left(\mathrm{HbA}_{1 \mathrm{c}}\right)$, and 24-h urinary albumin excretion rate $\left(\mathrm{U}_{\mathrm{alb}} \cdot \mathrm{V}\right)$ at 14 mo after induction of diabetes are summarized in Table III. Body weights were moderately lower in DM and $\mathrm{DM}+\mathrm{E}$ rats as compared with controls. As observed at 4-6 wk of diabetes, LKW was markedly increased in DM rats as compared with controls $(2.60 \pm 0.10 \mathrm{~g}$ vs. $1.85 \pm 0.10 \mathrm{~g}, P<0.05)$, indicating persistence of renal hypertrophy throughout the study. Renal hypertrophy of slightly lesser magnitude was observed in the $\mathrm{DM}+\mathrm{E}$ group.

As shown in Fig. 1, a state of stable moderate hyperglycemia was maintained throughout the duration of the experiment in both diabetic groups. That the metabolic derangement was similar in both diabetic groups is further illustrated by the finding in Table III of comparable levels of $\mathrm{HbA}_{1 \mathrm{c}}(15.0 \pm 0.7 \%$ in DM and $12.8 \pm 0.3 \%$ in $\mathrm{DM}+\mathrm{E}$ rats, vs. $4.9 \pm 0.3 \%$ in controls). $\mathrm{A}$ moderate but persistent decrease in systolic TBP was observed in $\mathrm{DM}+\mathrm{E}$ rats throughout the study relative to $\mathrm{DM}$ or $\mathrm{C}$ values (Fig. 1). Albumin excretion increased with time in DM rats, $\mathrm{U}_{\mathrm{alb}} \cdot \mathrm{V}$ rising on average to $111 \pm 22 \mathrm{mg} / 24 \mathrm{~h}$ at $14 \mathrm{mo}$ of diabetes 
Table III. Renal and Systemic Parameters at 14 Mo of Diabetes

\begin{tabular}{|c|c|c|c|c|c|c|}
\hline Group & Body weight & LKW & $\mathbf{H b A}_{\mathrm{lc}}$ & TBP & $U_{\infty} \cdot v$ & GS \\
\hline & $g$ & $g$ & percent & $m m H g$ & $m g / 24 h$ & percent \\
\hline $\mathrm{C}(n=11$ rats $)$ & $431 \pm 14$ & $1.85 \pm 0.10$ & $4.9 \pm 0.3$ & $116 \pm 2$ & $25 \pm 6$ & $1.10 \pm 0.18$ \\
\hline $\mathrm{DM}(n=13)$ & $355 \pm 7^{*}$ & $2.60 \pm 0.10^{*}$ & $15.0 \pm 0.7^{*}$ & $131 \pm 3^{*}$ & $111 \pm 22^{*}$ & $6.06 \pm 1.20^{*}$ \\
\hline $\mathrm{DM}+\mathrm{E}(n=10)$ & $328 \pm 10^{*}$ & $2.37 \pm 0.08^{*}$ & $12.8 \pm 0.3^{*} \ddagger$ & $109 \pm 2 \ddagger$ & $18 \pm 3 \ddagger$ & $0.67 \pm 0.20 \ddagger$ \\
\hline
\end{tabular}

GS, glomerular sclerosis. Values given as mean \pm 1 SEM. ${ }^{*} P<0.05$ vs. $\mathrm{C} ; \ddagger P<0.05$ vs. DM.

(Fig. 3 and Table III). By contrast, despite a similar degree of stable moderate hyperglycemia, $U_{\text {alb }} \cdot V$ averaged only $18 \pm 3 \mathrm{mg} /$ $24 \mathrm{~h}$ in $\mathrm{DM}+\mathrm{E}$ rats at $14 \mathrm{mo}$, a value similar to that seen in controls $(25 \pm 6 \mathrm{mg} / 24 \mathrm{~h})$.

Morphologic findings. A total of 501 glomerular profiles on average were examined and graded per animal. Segmental collapse of the glomerular tuft was observed in over $6 \%$ of glomerular profiles at 14 mo in untreated diabetic animals $(6.06 \% \pm 1.20)$. The comparable frequencies of glomerular lesions in enalapril-treated diabetic animals and controls were $0.67 \pm 0.20 \%$ and $1.10 \pm 0.18 \%$, respectively (Table III). Untreated diabetic animals, in addition, showed focal dilatation of proximal convoluted tubules and the presence of occasional casts in the distal segments of the nephron. Focal tubule atrophy with minor nonspecific round cell infiltration and fibrosis of the interstitium was often seen in association with obsolescent glomeruli in this group. In contrast, control animals and enalapril-treated diabetic rats had only minimal disruption of the tubules and interstitium. Vascular changes were not prominent in any of the groups.

\section{Discussion}

Sustained hyperfiltration has been demonstrated in early phases of insulin-dependent human diabetes and in animal models, before diabetic microvascular disease has become evident. Hostetter and co-workers (5) showed that this hyperfiltration was the result of concomitant elevations in glomerular plasma flow rate and mean glomerular transcapillary hydraulic pressure difference. Several studies have suggested that these hemodynamic abnormalities are key factors in the initiation and progression of diabetic glomerulopathy $(7,23,24)$. Recently, Zatz et al. (7)

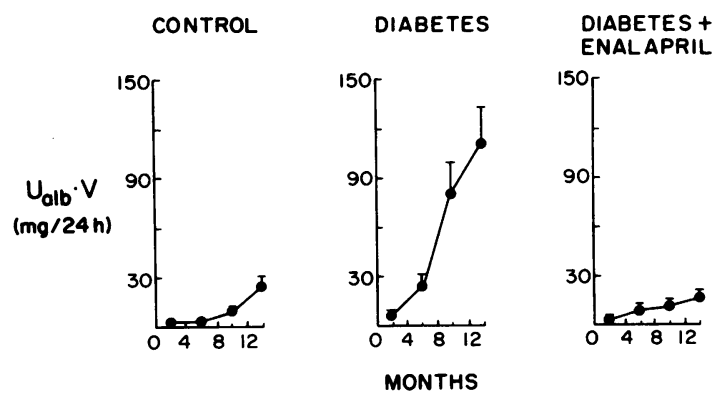

Figure 3. Sequential average daily albumin excretion rates $\left(U_{a b} \cdot V\right)$ in control (C), untreated (DM), and enalapril-treated (DM+E) diabetic rats. In contrast to the marked rise in $\mathrm{U}_{\mathrm{alb}} \cdot \mathrm{V}$ in the DM group, values in the $\mathrm{DM}+\mathrm{E}$ group were indistinguishable from control. studied moderately hyperglycemic STZ-diabetic rats 1 and 12 mo after induction of diabetes. Wide variations in glomerular hemodynamics were intentionally induced by feeding diets containing 50,12 , or $6 \%$ casein (standard commercial rat chow contains $21-24 \%$ protein). Only rats receiving the protein-rich $(50 \%)$ diet exhibited elevated glomerular pressures and flows at 1 mo of diabetes. Despite comparable metabolic abnormalities in all three diabetic groups, only the group on the highest protein diet developed substantial glomerular injury $12 \mathrm{mo}$ after induction of diabetes. When glomerular hemodynamic abnormalities were attenuated by moderate $(12 \%)$ or more marked $(6 \%)$ dietary protein restriction, glomerular structural injury was largely prevented. These studies clearly underscore the importance of early elevation of glomerular pressures and flows in the subsequent development of glomerular injury in this model.

In this study, diabetic rats receiving standard $24 \%$ protein chow exhibited glomerular hemodynamic alterations resembling those previously observed in diabetic rats fed a $50 \%$ protein diet, and those previously reported by Hostetter et al. (5). As in these previous studies, a marked decrease in glomerular arteriolar resistances, in particular $R_{\mathrm{A}}$, was associated with corresponding elevations in $Q_{\mathrm{A}}, \overline{\Delta \mathrm{P}}$, and SNGFR. In the current study, glomerular hemodynamic alterations were attenuated by converting enzyme inhibition rather than by restricting dietary protein intake. This maneuver has been shown previously in this laboratory (11) to normalize glomerular capillary hydraulic pressure in rats with $5 / 6$ renal ablation, without significantly affecting SNGFR or $Q_{\mathrm{A}}$. Unlike rats with severe reduction of renal mass, however, STZ-diabetic rats in the present studies were normotensive or only slightly hypertensive, a finding in keeping with the clinical observation of near-normal systemic blood pressure in most patients with early, uncomplicated insulin-dependent diabetes (25). With enalapril treatment, a persistent $20 \mathrm{mmHg}$ reduction in $\overline{\mathrm{AP}}$ was observed in $\mathrm{DM}+\mathrm{E}$ rats. This reduction in $\overline{\mathrm{AP}}$ was accompanied by a striking reduction in $\overline{\Delta P}$ to levels seen in nondiabetic control rats. This effect was accounted for by the observed reduction in mean systemic arterial pressure in the setting of persistent glomerular arteriolar vasodilatation, thus permitting this slight systemic hypotension to be shared by the glomerular capillaries. It should be stressed that values for SNGFR and $Q_{\mathrm{A}}$ remained substantially elevated in enalapril-treated rats despite normalization of $\overline{\Delta \mathbf{P}}$. The persistence of hyperfiltration can be explained by the numerically higher $K_{\mathrm{f}}$ values observed in these animals $(0.101 \pm 0.017 \mathrm{nl} /(\mathrm{s} \cdot \mathrm{mmHg})$ vs. $0.057 \pm 0.005$ in $\mathrm{DM})$, thus offsetting the effect of the reduction in $\overline{\Delta \mathbf{P}}$. Of note, in rats with 5/6 renal ablation, enalapril treatment was also associated with a similar increase in $K_{\mathrm{f}}(11)$.

Diabetic rats not treated with enalapril exhibited marked 
and progressive proteinuria, as well as a correspondingly high prevalence of glomerular structural abnormalities at 14 mo of diabetes. These findings indicate that long-term moderate hyperglycemia is inevitably accompanied by progressive glomerular damage in a large proportion of rats fed $24 \%$ protein chow, thus adequately reproducing the natural history of this disorder in humans. In sharp contrast with the near-exponential progression of albuminuria in untreated DM rats, enalapril treatment was associated with only slight increases in urinary albumin excretion with time, never reaching values significantly different from control. Likewise, morphological abnormalities in this group were minimal and not distinguishable from those associated with normal aging. While $\overline{\mathrm{AP}}$ was maintained at subnormal levels in $\mathrm{DM}+\mathrm{E}$ rats throughout the study, blood glucose concentration remained at nearly identical stable high levels in both diabetic groups. The proportion of glucosylated hemoglobin at the end of the study was also essentially identical in DM and DM+E rats, and well in excess of values seen in control rats. Thus, the observed differences between DM and DM+E groups regarding glomerular morphology cannot be attributed to differences in metabolic control; rather, the structural differences appear to result solely from the observed differences in glomerular hemodynamics, and in particular the differences in $\overline{\Delta \mathbf{P}}$ in the two groups. In this regard, the present findings closely resemble those previously obtained by Zatz and co-workers (7), in that only the group sustaining early glomerular hypertension eventually developed widespread glomerular injury at 14 mo of diabetes.

The precise mechanism(s) whereby intracapillary hypertension adversely affects glomerular structure has not been elucidated. Systemic arterial hypertension has long been known to increase arterial and arteriolar permeability to macromolecular tracers and to lead to structural damage of arterial walls $(9,26-$ 28). Elevations in intracapillary hydraulic pressures are likely to exert an analogous effect. In systemic capillaries, evidence for an association between capillary basement membrane thickness and capillary pressure has been provided in a number of situations, including variation of intravascular hydrostatic pressure by gravity (29), local venous stasis (30), and long-standing congestive heart failure (31). One possible mechanism for this effect could be the stimulation of local basement membrane production by the increased capillary wall tension, in a manner analogous to the enhanced collagen synthesis observed with increased local tension in other tissues (32). At the glomerular capillary level, this tension could also lead to direct mechanical disruption of the glomerular capillary wall, giving rise to capillary microaneurysms and epithelial cell detachment from the glomerular basement membrane $(28,33)$. Furthermore, the increased platelet aggregability observed in diabetes (34) might further contribute to the development of diabetic glomerular injury by promoting capillary thrombosis in the presence of even minor degrees of endothelial injury. This possibility is strengthened by the observation of a protective effect of heparin against glomerular injury in the remnant kidney (35) and in nephrotoxic serum nephritis (36).

Among the etiologic factors that have been considered, recent studies have focused attention on the role played by the glomerular mesangium in the genesis of diabetic glomerulopathy. Mesangial thickening, which may be a direct or indirect consequence of an increase in the rate of deposition of circulating macromolecules, is invariably associated with segmental sclerotic lesions in diabetes (37). Other studies have suggested that increased mesangial activity is a cause of progressive glomerular injury in nephrotoxic serum nephritis and aminonucleoside nephrosis, giving rise to the so-called "mesangial overload hypothesis" $(28,38)$. Increased transglomerular passage of macromolecules, with consequent mesangial hyperactivity, is likely to be operative over an extended period of time in diabetic subjects before the appearance of clinical signs of diabetic nephropathy $(39,40)$.

Clinical studies have shown that treatment of systemic hypertension in patients with moderately advanced diabetic nephropathy retards subsequent deterioration of renal function, presumably by ameliorating abnormal glomerular capillary hemodynamics $(13,14)$. The present study demonstrates for the first time that long-term converting enzyme inhibition in an animal model of diabetes mellitus not only delays, but actually prevents, the establishment of diabetic glomerulopathy, largely by normalizing glomerular capillary hydraulic pressure.

\section{Acknowledgments}

Michelle Hardiman provided expert secretarial assistance.

These studies were supported in part by grants from the National Institutes of Health (AM 30410), Kroc Foundation, and Merck, Sharp and Dohme. Dr. Zatz received an International Research Fellowship Award from the Fogarty International Center of the National Institutes of Health (TWO3263-01S1) and a grant from the State of Sao Paulo Foundation for Research Support, Sao Paulo, Brazil (83/2570-1). Dr. Dunn was supported by a Burroughs Wellcome Fellowship awarded by The National Kidney Foundation. Dr. Anderson was the recipient of an Individual National Research Service Award of the National Institutes of Health (S F32 AM 07206).

\section{References}

1. Stalder, G., and R. Schmid. 1959. Severe functional disorders of glomerular capillaries and renal hemodynamics in treated diabetes mellitus during childhood. Ann. Paediat. (Paris). 193:129-138.

2. Mogensen, C. E. 1971. Glomerular filtration rate and renal plasma flow in short-term and long-term juvenile diabetes mellitus. Scand. $J$. Clin. Lab. Invest. 28:91-100.

3. Christiansen, J. S., J. Gammelgaard, M. Frandsen, and H.-H. Parving. 1981. Increased kidney size, glomerular filtration rate and renal plasma flow in short-term insulin-dependent diabetics. Diabetologia. 20: 451-456.

4. Christiansen, J. S., S. Gammelgaard, B. Tronier, P. A. Svendsen, and H.-H. Parving. 1982. Kidney function and size in diabetics before and during initial insulin treatment. Kidney Int. 21:683-688.

5. Hostetter, T. H., J. L. Troy, and B. M. Brenner. 1981. Glomerular hemodynamics in experimental diabetes mellitus. Kidney Int. 19:410415 .

6. Jensen, P. K., J. S. Christiansen, K. Steven, and H.-H. Parving. 1981. Renal function in streptozotocin-diabetic rats. Diabetologia. 21: 409-414.

7. Zatz, R., T. W. Meyer, H. G. Rennke, and B. M. Brenner. 1985. Predominance of hemodynamic rather than metabolic factors in the pathogenesis of diabetic glomerulopathy. Proc. Natl. Acad. Sci. USA. 82:5963-5967.

8. Hostetter, T. H., H. G. Rennke, and B. M. Brenner. 1982. The case for intrarenal hypertension in the initiation and progression of diabetic and other glomerulopathies. Am. J. Med. 72:375-380.

9. Zatz, R., and B. M. Brenner. 1986. Diabetic microangiopathy: the hemodynamic view. Am. J. Med. 80:443-453.

10. Hostetter, T. H., J. L. Olson, H. G. Rennke, M. A. Venkatachalam, and B. M. Brenner. 1981. Hyperfiltration in remnant nephrons: a potentially adverse response to renal ablation. Am. J. Physiol. 241: F85-F93.

11. Anderson, S., T. W. Meyer, H. G. Rennke, and B. M. Brenner. 
1985. Control of glomerular hypertension limits glomerular injury in rats with reduced renal mass. J. Clin. Invest. 76:612-619.

12. Mogensen, C. E., and C. K. Christensen. 1984. Predicting diabetic nephropathy in insulin-dependent patients. N. Engl. J. Med. 311:8993.

13. Parving, H.-H., A. R. Andersen, U. M. Smidt, J. S. Christiansen, B. Oxenbell, and P. A. Svendsen. 1983. Diabetic nephropathy and arterial hypertension: the effect of antihypertensive treatment. Diabetes. 32(Suppl. 2):83-87.

14. Drury, P. L. 1983. Diabetes and arterial hypertension. Diabetologia. 24:1-9.

15. Rasch, R. 1979. Control of blood glucose levels in the streptozotocin diabetic rat using a long-acting heat treated insulin. Diabetologia. 16:185-190.

16. Baylis, C., W. M. Deen, B. D. Myers, and B. M. Brenner. 1976. Effects of some vasodilator drugs on transcapillary fluid exchange in renal cortex. Am. J. Physiol. 230:1148-1158.

17. Ichikawa, I., D. A. Maddox, M. G. Cogan, and B. M. Brenner. 1978. Dynamics of glomerular ultrafiltration in euvolemic Munich-Wistar rats. Renal Physiol. 1:121-131.

18. Vurek, G. C., and S. E. Pegram. 1966. Fluorometric method for the determination of nanogram quantities of inulin. Anal. Biochem. 16: 409-419.

19. Viets, J. W., W. M. Deen, J. L. Troy, and B. M. Brenner. 1978. Determination of serum protein concentration in nanoliter blood samples using fluorescamine or o-phthalaldehyde. Anal. Biochem. 88:513-521.

20. Mancini, G., A. O. Carbonara, and J. F. Heremans. 1965. Immunochemical quantitation of antigens by single radial immunodiffusion. Immunochemistry. 2:235-254.

21. Garlick, R. L., J. S. Mazer, P. J. Higgins, and H. F. Bunn. 1983. Characterization of glycosylated hemoglobins. Relevance to monitoring of diabetic control and analysis of other proteins. J. Clin. Invest. 71: 1062-1072.

22. Wallenstein, S., C. L. Zucker, and J. L. Fleiss. 1980. Some statistical methods useful in circulation research. Circ. Res. 47:1-9.

23. Steffes, M. W., D. M. Brown, and S. M. Mauer. 1978. Diabetic glomerulopathy following unilateral nephrectomy in the rat. Diabetes. 27:35-41.

24. Mauer, S. M., M. W. Steffes, S. Azar, S. K. Sandberg, and D. M. Brown. 1978. The effects of Goldblatt hypertension on development of the glomerular lesions of diabetes mellitus in the rat. Diabetes. 27:738744.

25. Parving, H.-H., U. M. Smidt, B. Friisberg, V. Bonnevie-Nielsen, and A. R. Andersen. 1981. A prospective study of glomerular filtration rate and arterial blood pressure in insulin-dependent diabetics with diabetic nephropathy. Diabetologia. 20:457-461.

26. Wilson, S. K., and R. H. Heptinstall. 1984. Effects of acute, angiotensin-induced hypertension on intrarenal arteries in the rat. Kidney Int. 25:492-501.

27. Olson, J. L., A. G. de Urdaneta, and R. H. Heptinstall. 1985. Glomerular hyalinosis and its relation to hyperfiltration. Lab. Invest. 52:387-397.

28. Mitch, W. E., B. M. Brenner, and J. H. Stein, editors. 1986. The Progressive Nature of Renal Disease. Churchill Livingstone, Inc., New York. Chapters 6 and 7.

29. Williamson, J. R., N. J. Vogler, and C. Kilo. 1971. Regional variations in the width of the basement membrane of muscle capillaries in man and giraffe. Am. J. Pathol. 63:359-370.

30. Landis, E. M., L. Jonas, N. Angevine, and W. Erb. 1932. The passage of fluid and protein through the human capillary wall during venous congestion. J. Clin. Invest. 11:717-734.

31. Longhurst, J., R. J. Capone, and R. Zelis. 1975. Evaluation of skeletal muscle capillary basement membrane thickness in congestive heart failure. Chest. 67:195-198.

32. Williamson, J. R., and C. Kilo. 1977. Current status of capillary basement-membrane disease in diabetes mellitus. Diabetes. 26:65-75.

33. Nakamoto, Y., E. Takazakura, H. Hayakawa, K. Kawai, K. Dohi, M. Fujioka, H. Kida, N. Hattori, and J. Takeuchi. 1980. Intrarenal microaneurysms in diabetic nephropathy. Lab. Invest. 42:433-439.

34. Colwell, J. A., P. V. Halushka, K. Sarji, J. Levine, J. Sagel, and R. M. G. Nair. 1976. Altered platelet function in diabetes mellitus. Diabetes. 25(Suppl. 2):826-831.

35. Olson, J. L. 1984. Role of heparin as a protective agent following reduction of renal mass. Kidney Int. 25:376-382.

36. Nakamoto, Y., K. Dohi, H. Fujiike, T. Yuri, A. Shinoda, and J. Takeuchi. 1978. Microangiographic evaluation of the effects of heparin on progressive Masugi nephritis. Kidney Int. 13:297-305.

37. Heptinstall, R. H. 1983. Diabetes mellitus and gout. In Pathology of the Kidney. Third Ed. Little, Brown and Co., Boston. 1397-1453.

38. Baldwin, D. S. 1982. Chronic glomerulonephritis: nonimmunologic mechanisms of progressive glomerular damage. Kidney Int. 21: 109-120.

39. Viberti, G. C., and H. Keen. 1984. The patterns of proteinuria in diabetes mellitus. Relevance to pathogenesis and prevention of diabetic nephropathy. Diabetes. 33:686-692.

40. Ditzel, J., and K. Junker. 1972. Abnormal glomerular filtration rate, renal plasma flow, and renal protein excretion in recent and shortterm diabetics. Br. Med. J. 2:13-19. 